\title{
Análise do comportamento da força de aderência de um ajuste prensado em rodas de aço ABNT 4340
}

\section{Analysis of the interference fit force of a pressed fit in steel wheels AISI 4340}

Artigo

Original

Celso Luiz de Azevedo Martins ${ }^{1}$

Rosinei Batista Ribeiro ${ }^{2}$

Original

Emerson Augusto Raymundo ${ }^{2}$

\section{Palavras-chave:}

Força de aderência

Ajuste prensado

ABNT 4340

Ajuste com

interferência

\section{Resumo}

Esta pesquisa confirmou, por meio de resultados experimentais, que nos ajustes prensados entre peças de aço a força de aderência aumenta muito nos primeiros dias após a montagem e segue aumentando lentamente ao longo do tempo. Os conjuntos roda-eixo foram montados e desmontados com a utilização de uma máquina universal hidráulica de ensaios mecânicos. As desmontagens foram realizadas em sequência, após períodos que variaram entre a primeira hora até quarenta e um (41) dias após montagem. Desse modo foi possível verificar o aumento da força necessária para a desmontagem, em função do tempo decorrido entre a montagem e a desmontagem.

\section{Abstract}

The research confirmed, through experimental results, that in the pressed fits between steel parts, the fit force increases after the execution of the parts union and this one increases very much in the first days and it continues to increase, although more slowly, in the course of time. The wheel-axle sets were assemblies and disassemblies with the using of a hydraulic universal materials testing machine. The disassemblies were performed in sequence, after periods that varied between the first hour until forty one (41) days after assembly. Thus, it was possible to check the increase of the necessary force for disassembling due to the time between the assembly and the disassembly.

\section{Keywords:}

Interference fit force

Pressed fit

AISI 4340

Interference fit 


\section{Introdução}

Esta pesquisa é o resultado da análise do comportamento da força de aderência, em função do tempo decorrido entre a montagem prensada e a posta em marcha, de conjuntos de peças de aço formados por uma roda ajustada a um eixo maciço. (1)

Para o estudo foram fabricadas rodas e eixos e realizados ensaios constituídos de uma montagem e de uma desmontagem de cada um dos conjuntos roda - eixo, utilizando-se uma máquina universal hidráulica de ensaios mecânicos. As desmontagens ocorreram em períodos distintos, de modo que cada ensaio representasse um intervalo de tempo de armazenamento entre uma (01) hora e quarenta e um (41) dias. Para cada um dos ajustes prensados foram gerados dois gráficos força $x$ deslocamento: um na montagem e o outro na desmontagem. Esses gráficos permitiram a análise do comportamento da força de aderência em função do tempo decorrido entre a montagem e a posta em marcha. $\mathrm{O}$ conhecimento do comportamento da força de aderência é de grande importância para o cálculo da interferência entre as peças, pois a ocorrência do aumento da força de aderência pode produzir níveis de tensões tangenciais suficientes para provocar fraturas nos componentes do conjunto. Outro ponto de grande importância está no alerta aos engenheiros de que este fenômeno deve ser considerado nos estudos das causas prováveis de fraturas em engrenagens montadas em seus respectivos eixos, mas que ainda não foram postas em operação.

A Fotografia 1 representa um caso real e mostra uma das seis engrenagens de redutores de velocidades cujas fraturas ocorreram seis semanas após a montagem e durante o armazenamento. As fraturas ocorreram antes da posta em marcha e, portanto, sem estarem sujeitas aos esforços externos resultantes da operação do redutor de velocidades.

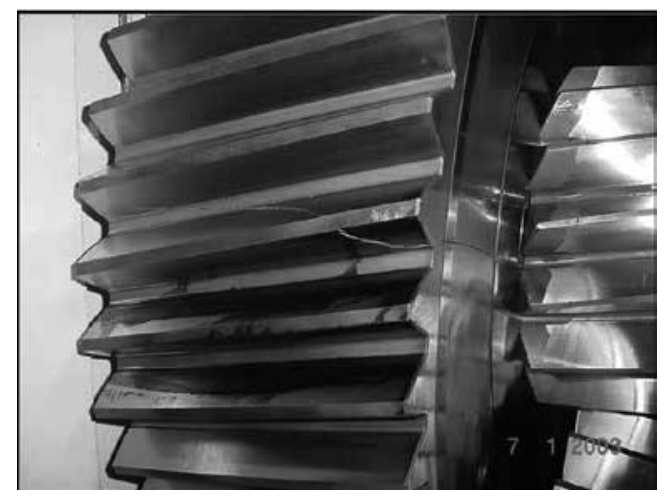

Fotografia 1 - Detalhe da fratura

\section{Metodologia}

A metodologia deste estudo consistiu em submeter uma determinada quantidade de corpos de prova a ensaios mecânicos, com o objetivo de analisar o comportamento da força de aderência em função do tempo decorrido após a montagem do conjunto. Cada um dos ensaios correspondeu a uma montagem prensada de um eixo no furo de uma roda e da respectiva desmontagem pela mesma prensa.

Para a roda foi especificado o aço ABNT 4340, pois é um tipo de aço muito utilizado na fabricação de engrenagens devido a sua alta temperabilidade e alta resistência mecânica, além de possuir boa usinabilidade, boa tenacidade e boa ductibilidade. Para o eixo foi especificado o aço ABNT 1045, pois a maior parte dos eixos de máquinas é feita de aço de baixo ou médio carbono; sendo o aço ABNT 1045 um dos mais utilizados na fabricação de eixos. (2)

$\mathrm{O}$ ajuste selecionado foi o $\mathrm{H} 7 / \mathrm{z} 7$, padronizado pela NBR 6158/1995 (3), cuja interferência é de alta intensidade.

As rodas, os eixos e o suporte utilizado nas montagens e nas desmontagens estão exemplificados na Fotografia 2.

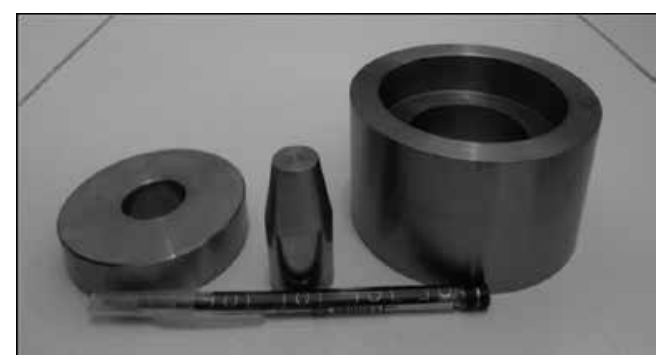

Fotografia 2 - Roda, eixo e suporte 
Após a lubrificação das peças, cada um dos conjuntos foi preparado para montagem inserindo-se a roda no suporte e posicionando-se o eixo no furo da roda, com a ponta biselada para baixo, conforme mostra a Fotografia 3.

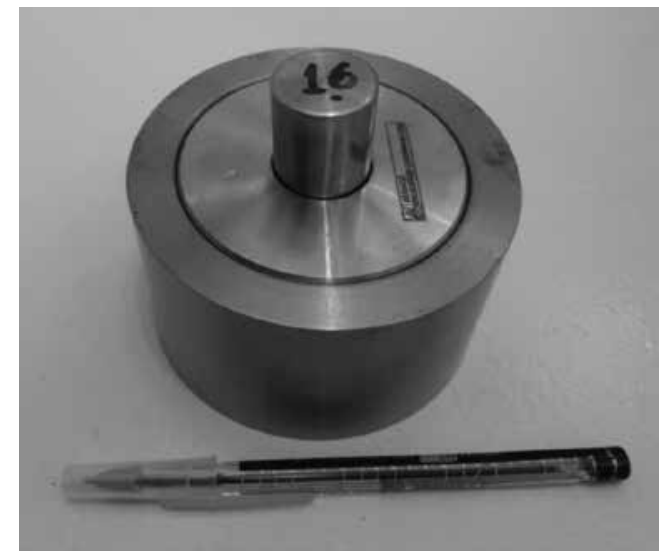

Fotografia 3 - Eixo posicionado para montagem

As montagens foram realizadas pela Máquina para Ensaios de Materiais WOLPERT LESTOR, pressionando-se o eixo até o contato pleno das superfícies de ajuste, cujo resultado está mostrado na Fotografia 4.

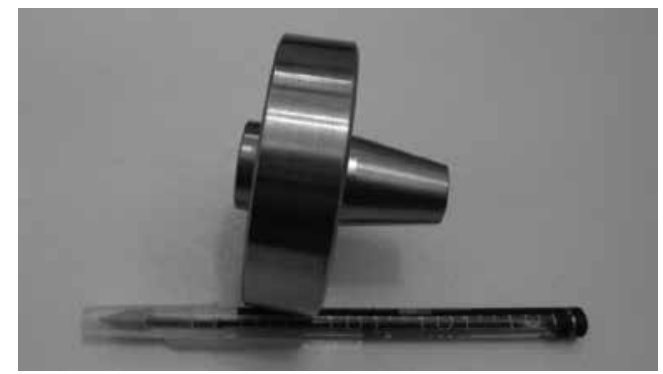

Fotografia 4 - Conjunto montado

As desmontagens foram realizadas pressionando-se a ponta biselada do eixo, com a mesma máquina, até que o contato entre as peças deixe de existir.

A coleta de dados foi realizada nos gráficos força $\mathrm{x}$ deslocamento, gerados pela máquina de ensaios mecânicos WOLPER LESTOR nas montagens e nas desmontagens dos conjuntos.

Foram realizadas caracterizações metalográficas no material roda, para comparar a forma e a orientação preferencial dos grãos da superfície próxima ao furo com a superfície próxima ao diâmetro externo: antes da montagem e após a desmontagem. Também foram realizados ensaios de dureza na roda e no eixo, antes e após desmontagem, com o objetivo de verificar a ocorrência de aumento de dureza decorrente de uma possível deformação plástica durante a montagem.

\section{Resultados e Discussão}

O Gráfico 1 é o resultado dos quarenta e dois (42) gráficos gerados pela Máquina para Ensaios de Materiais WOLPERT LESTOR e mostra o comportamento da força de aderência em função do tempo. O eixo vertical do gráfico representa o percentual de aumento da força de desmontagem em comparação com a força de montagem e o eixo horizontal representa tempo decorrido entre a montagem e a desmontagem de cada um dos conjuntos roda-eixo. O gráfico mostra que, para todos os conjuntos, a força de desmontagem (força de aderência) é maior do que a força de montagem e que a força de desmontagem aumenta em função do tempo. Portanto, confirma a afirmativa de que a força de aderência de um ajuste prensado, entre peças de aço, aumenta com o tempo decorrido após montagem. (1)

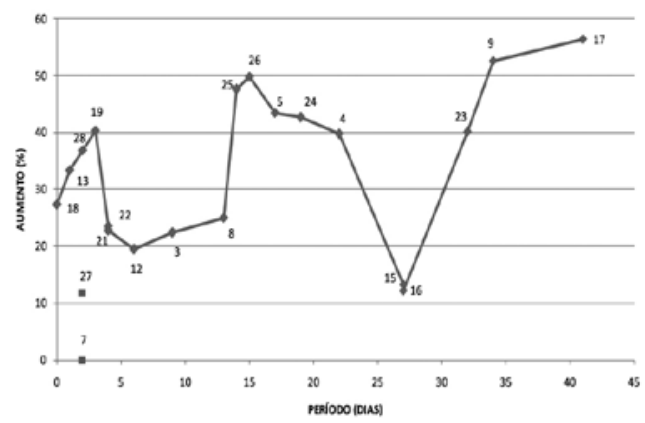

Gráfico 1 - Comportamento da força de aderência em função do tempo

Além disso, foi possível confirmar que a taxa de aumento da força de aderência foi mais alta nos primeiros dias e diminuiu com o decorrer do tempo: no terceiro dia após montagem foi registrado um aumento de $40 \%$ e, embora com oscilações, o aumento total chegou a $56 \%$ no $41^{\circ}$ dia.

As Micrografias 1 e 2 mostram as imagens da superfície lateral da roda $\mathrm{n}^{\circ} 17$, que foi desmontada no $41^{\circ}$ dia após montagem: (a) micrografia de um ponto distante $\cong 2,2 \mathrm{~mm}$ do furo; (b) micrografia de um ponto distante $\cong$ 2,0 mm do diâmetro externo da roda. 
Micrografia 1 - Roda $n^{\circ} 17$ (após desmontagem) $100 \mathrm{X}-$ Nital $2 \%$

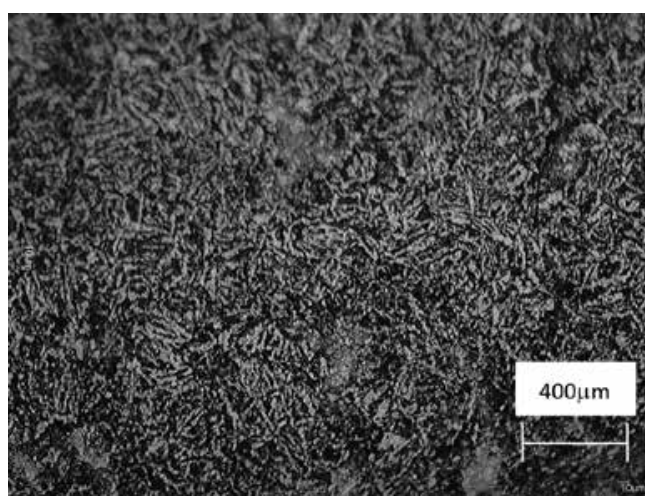

(a) próximo ao furo $(\cong 2,2 \mathrm{~mm})$ (raio de concordância do furo $+1,2 \mathrm{~mm}$ )

Micrografia 2 - Roda no 17 (após desmontagem) 100X - Nital 2\%

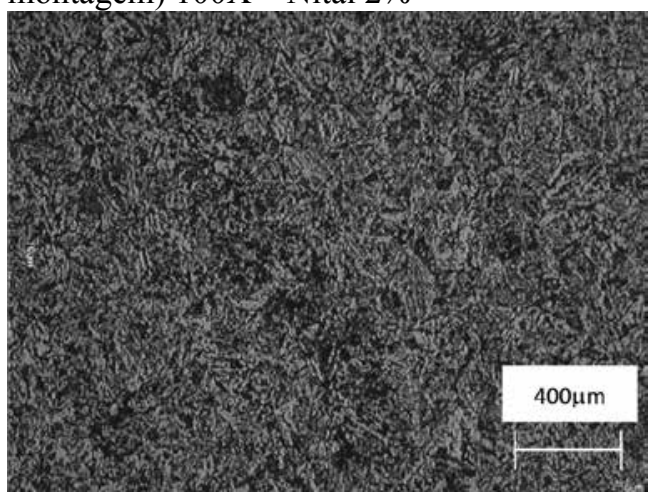

(b) próximo da superfície externa $(\cong 2,0 \mathrm{~mm})$

As imagens da amostra permitiram executar a comparação da morfologia do material entre as regiões laterais próximas ao furo e as regiões laterais próximas ao diâmetro externo da roda. Verificou-se que os grãos do material da roda estão um pouco mais reduzidos e alongados nas regiões próximas ao diâmetro externo da roda. Fato que pode ser explicado pelo processo de fabricação da matéria prima (barra redonda), ou seja, do processo de resfriamento da matéria prima: mais rápido na superfície externa e mais lento na superfície interna.

Os resultados dos ensaios de dureza nas superfícies laterais das rodas mostraram que a dureza é maior nas regiões com distâncias próximas aos raios da superfície externa. Fato que também que também pode ser explicado pelo processo de resfriamento da matéria prima.

Portanto, o exame das imagens microscópicas e o resultado da análise dos ensaios de dureza permitiram concluir que a tensão resultante da interferência entre as peças não provocou deformações permanentes nas regiões com distância maior do que 2,2 mm (raio de concordância do furo $+1,2 \mathrm{~mm}$ ).

\section{Conclusões}

Com base nos resultados dos ensaios de montagem e de desmontagem dos conjuntos roda - eixo foi possível confirmar experimentalmente a afirmação de que nos ajustes prensados entre peças de aço, a força de desmontagem (força de aderência) aumenta após a execução da união das peças e que esta aumenta muito nos primeiros dias e segue aumentando, embora mais lentamente, com o decorrer do tempo. (1) Este fenômeno é de grande importância para o cálculo da interferência entre peças de aço, pois o aumento da força de aderência que, nesta pesquisa, em 41 dias de armazenamento, foi de $56 \%$ da força de montagem, pode produzir níveis de tensões tangenciais que, em conjunto com pontos de concentração de tensões, como rasgos de chavetas, podem iniciar trincas que poderão resultar em fraturas. Outro ponto de grande importância está no alerta aos engenheiros que este fenômeno deve ser considerado nos estudos das causas prováveis de fraturas em engrenagens montadas em seus respectivos eixos, mas que ainda não foram postas em operação.

\section{Comentários}

Mateos (1) afirma que, para peças de aço, o aumento da força de aderência sempre ocorre nos ajustes prensados e é inexistente nas montagens obtidas pela dilatação térmica das peças (ajustes fretados). Portanto, os resultados desta pesquisa, em conjunto com a afirmação acima, dão origem à necessidade de dois estudos adicionais: $1^{\circ}$ ) Comprovação da inexistência do aumento da força de aderência em função do tempo em ajustes fretados e $2^{\circ}$ ) Determinação da causa fundamental do aumento da força de aderência em ajustes prensados. 
1. MATEOS, Abelardo Garcia. Tolerâncias e Ajustes. Tradução de Augusto Câmara Neiva. $2^{a}$ ed. São Paulo : Editora Polígono, 1974.

2. NORTON, Robert L. Projeto de máquinas. Uma abordagem integrada. Tradução de Maik Briscese Müller et al. $2^{\mathrm{a}}$ ed. Porto Alegre : Artmed Editora S.A., 2004.

3. ASSOCIAÇÃO BRASILEIRA DE NORMAS TÉCNICAS. NBR 6158:

Sistemas de tolerâncias e ajustes. Rio de Janeiro, 1995. 